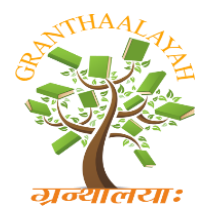

INTERNATIONAL JOURNAL OF RESEARCH GRANTHAALAYAH

A knowledge Repository

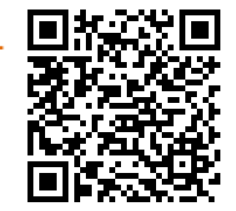

Management

\title{
EFFECTIVENESS OF ONLINE ADVERTISING
}

\author{
G. Anusha *1 \\ ${ }^{* 1}$ Assistant Professor, Malankara Catholic College, Mariagiri, INDIA
}

\begin{abstract}
Advertising has come a long way today. More and more new medium is being explored each day to make a successful advertising campaign. Internet that has in recent times picked up as advertising medium has become the favorite of the advertiser in no time. Online advertisement, also called internet advertising uses the internet to deliver promotional marketing messages to consumers. It includes email marketing, search engine marketing, social media marketing, many types of display advertising (including web banner advertising), and mobile advertising. This study reveals that the effectiveness of on line advertising and usefulness and the reasons for using online advertisement. For this the study takes percentage and Lickert's scaling techniques.
\end{abstract}

Keywords:

Online advertising, Traditional advertising, Media advertisement.

Cite This Article: G. Anusha, "EFFECTIVENESS OF ONLINE ADVERTISING” International Journal of Research - Granthaalayah, Vol. 4, No. 3: SE (2016): 14-21.

\section{INTRODUCTION}

Like other advertising media, online advertising frequently involves both a publisher, who integrates advertisements into its online content, and an advertiser who provides the advertisements to be displayed on the publisher's content. Other potential participants include advertising agencies that help generate and place the advertisement copy, the advertisement server who technologically delivers the advertisement and tracks statistics, and advertising affiliates who do independent promotional work for the advertiser.

Internet as an advertising medium is versatile and this is it where it stands apart from the conventional advertising medium. It is a highly flexible medium that allows you to make changes during the course of the campaign as and when required without incurring much additional cost. This makes internet all the more important in a country like India where the business scenario is highly dynamic and changes with each passing day. Online marketing media allows the user to make changes as and when required to meet the latest demands of the market. The main strength of Internet as an advertising medium is its ability to reach out to a vast audience at one goes. Internet advertising is also not bound by limitations such as time and accessibility as one can surf the 
internet at any time of the day making your advertisement available $24 * 7$ unlike television advertisements to which the viewers can't go back or the newspaper advertisements that go in the waste once they are read in the morning. Day in and day out, businesses are going online to advertise their products and services. The internet combines aspects of print, television, and radio advertising in an interactive environment. It presents a new and fast-paced experience for customers. Thus, online advertisement is becoming one of the most preferred medium of advertisement and one with extreme potential for growth.

\section{OBJECTIVES OF THE STUDY}

The study is designed with the following objectives:

1) To know the most effective media of advertisement.

2) To explore the difference between online advertising and traditional form of advertising.

3) To find out the reasons for preferring on line advertisement.

4) To offer valuable suggestions based on the findings of the study.

\section{SIGNIFICANCE OF THE STUDY}

Advertising on the Internet is almost a necessity for modern businesses, especially those that do business outside their local community. Consumers use the Internet for more than simply entertainment or information, as they do with radio, television, magazines and newspapers. Consumers use the Internet to assist them in nearly every aspect of life, creating countless opportunities to place relevant, targeted advertising messages. Companies can take advantage of web advertising to complement their standard media and print marketing. The wide reach and continual exposure of online advertising work tirelessly to give businesses heightened visibility and audience contact. Companies can differentiate their brand online with useful information, positive interaction for their website visitors and enhanced communication to attract new customers

\section{SCOPE OF THE STUDY}

With the introduction of internet in our daily life, it has become a need for everyone. People use internet for everyday tasks. Internet is no longer just a medium of getting information for people. It has now taken shape of the most powerful medium of communication, entertainment and shopping for people. Every day, several new websites are being introduced covering different sections like news, e-commerce, information, communication or entertainment. These websites are a perfect place to advertise products and services as many people visit these sites every day from different parts of the world. Another important place for advertisement of the brand name, products or services can be online communities, forums, social networking sites or affiliate marketing websites. They provide immense organic traffic to the website representing the business or brand name.

\section{METHODOLOGY OF STUDY}

The primary data for the study was collected by using a structured questionnaire. The sample size for the study consists of 100 respondents. The questionnaire was prepared in such a way so as to gather data from 
the respondents, which will be helpful in attaining the objectives of the study. The collected data was carefully scrutinized, tabulated and analyzed using simple statistical techniques like percentages.

\section{LIMITATIONS OF THE STUDY}

The main limitation of the study was time constraint.

1) The sample size is limited to 100 internet users and hence the result of the study cannot be taken as universal.

2) Findings of the survey are based on the assumption that the respondents have given correct information.

3) Some of the respondents were reluctant to answer.

4) The study was conducted only in Trivandrum city and therefore, several potential samples outside the city were neglected.

\section{TOOLS \& TECHNIQUES}

\section{PERCENTAGE}

Ratio is very often expressed as percentages ratio established the relationships between two variables. In the calculation of percentages also one figure is taken as base and is devied by another number and multiplied by hundred.

\section{LICKERTS SCALING TECHNIQUE}

A5 points lickerts realing technique is used to find out more preferable features which attract the respondents towards features of the brand. Points were given as below

$\begin{array}{lll}\text { Excellent } & : & 5 \text { points } \\ \text { Very Good } & : & 4 \text { points } \\ \text { Good } & : & 3 \text { points } \\ \text { Average } & : & 2 \text { points } \\ \text { Poor } & : & 1 \text { point }\end{array}$

\section{HISTORY OF ONLINE ADVERTISING}

In its 17-year existence, Online Advertising has become the fastest, and one of the most effective advertising mediums in history. Today, it is one of the essentials of a successful business, a media platform that allows interaction with customers in the most creative and interesting ways.

\section{The Origin of Spam:}

By 1980, online marketers had charged from_ flooding Usenet forums to sending out emails, a practice that continues up until today. The numbers of spam emails that are sent everyday is a whopping 90 million. As a marketing technique however, spam emails have little effectiveness since most of the users barely read any. 


\section{Banner advertisements:}

The year 1994 saw the first online advertisement that was quickly followed by a period of experimentation on advertiser and publisher advertisement formats and technology. This initial phase ended with the launch of one of the first advertisement technologies, the double click in 1995. In the late 1990s, billions were invested in online advertisement. Banner advertisements today, are not effective online advertising mediums. With considerable designing required, they are time consuming and expensive to create. Besides, the low return on revenue spent on developing banner advertisements renders them useless to most online advertisers. Not surprisingly therefore, by mid-2000, banner advertisements started to dry up and has become obsolete at the time of writing.

\section{The advent of Google:}

The efficiency of search engine technology has sustained online advertising. Because of its high dependability and rate of interest, the search engine market has shown a steady growth over the years, pulling online advertising many notches. Drawing away from banner advertising, Google revolutionized online advertising by using relevant text advertisements to sell. Google's success rested on introducing the click - through rate that would measure the relevancy of the advertisement, also ensuring host payment only when users clicked on the advertisements Pay-Per-Click advertising was not a Google original. Google perfected Pay-Per-Click and changed the approach advertisers took to online advertising. Google Add words encouraged advertisers to come up with comprehensive, relevant advertisements instead of mere selling.

\section{Google on Pay-Per-Click and Pay-per-impression:}

Pay-per-click and Pay-per-impression are two different online advertising models. Pay-per-click, as the name suggests, involves payment to host every time users click on an advertisement. Pay-perimpression calculates the cost of the entire marketing campaign that is conducted online. Pay-Per-Click is instrumental in bringing targeted traffic to a website while Pay-Per-Impression is the best brand building model. Both however, are susceptible to click fraud.

\section{Social Media Advertising:}

Social media is everywhere and has been in vogue since the past five years. At its core, social media is a communications and networking tool, whose popularity has been constantly rising since its users can connect, share and interact among themselves.

\section{REVIEW OF LITERATURE}

Review of literature refers to identifying already existing literature to find out what contribution has already been made so that it can serve as a valuable base for further expanding the literature.

In the article 'Getting the eyeballs', published by 'The Hindu' on $19^{\text {th }}$ July 2007, Europe was taken as a sample for survey on the potential of online advertising. The survey revealed that 16 billion Euros will be spent on advertisements in Europe in 2012 and $18 \%$ of that will go online. $52 \%$ of the population of Europe was online regularly and the future for online revenue is India and China. However, there is still no idea as to how effective online advertisements are as more than twothirds of the European internet users feel they are not trustworthy. 


\section{Respondents Details:}

Respondents Detail is an important factor and it is being measured. The following table shows the details of the respondents.

Table 1.1: Respondents Details

\begin{tabular}{|l|l|l|}
\hline Category & No of respondents & Percentages \\
\hline Student & 80 & $80 \%$ \\
\hline Employee & 20 & $20 \%$ \\
\hline Total & 100 & $100 \%$ \\
\hline
\end{tabular}

Source: Primary data.

The above table represents the distribution of respondents by marital status. The data were collected from 100 respondents among the 100 respondents $24 \%$ were unmarried and $76 \%$ were married.

\section{Time spend in Online:}

This table shows how many times spend in online in a day by the respondents. This factor is important to analyse the effectiveness on online Advertising.

Table 1.2: Time Spend in Online

\begin{tabular}{|l|l|l|}
\hline Duration & No of respondents & Percentages \\
\hline One hour & 41 & $41 \%$ \\
\hline Two hour & 15 & $15 \%$ \\
\hline More than two hours & 21 & $21 \%$ \\
\hline Nil & 23 & $23 \%$ \\
\hline Total & 100 & $100 \%$ \\
\hline
\end{tabular}

Source: Primary data

Table 1.2 shows that $41 \%$ of the respondents use internet daily for one hours. $15 \%$ of the respondents use internet for two hours and $21 \%$ of the respondents use internet more than two hours a day and only $23 \%$ do not use internet at all. Therefore the analysis reveals that majority of the respondents use internet daily for one hour.

\section{Preferences in Advertisement:}

People prefer various type of advertisement. This table shows the performance of the advertisement in purchasing the products by the respondents.

Table 1.3: Preferences in Advertisement

\begin{tabular}{|l|l|l|}
\hline Advertisements & No of respondents & Percentages \\
\hline Online & 29 & $29 \%$ \\
\hline TV & 47 & $47 \%$ \\
\hline Magazine & 5 & $5 \%$ \\
\hline Banners & 2 & $2 \%$ \\
\hline Others & 13 & $13 \%$ \\
\hline Total & 100 & $100 \%$ \\
\hline
\end{tabular}


Source: Primary data

From the above table, it is clear that $29 \%$ of the respondents prefer online advertising. However, $47 \%$ of the respondents find TV as a convenient mode of advertising. 5\% prefer advertising in magazines, $2 \%$ prefer advertising in banner, $13 \%$ prefer other kinds of advertising and none of the respondents prefer advertising in banners. A conclusion can be reached that majority of the respondents prefer television advertisement.

\section{Time spending on online purchasing:}

Table No. 1.4 shows the time spending in online for purchasing the products. Most of the respondents spend time for online for know the information about the products.

Table 1.4: Time spending on online purchasing

\begin{tabular}{|l|l|l|}
\hline Category & No of respondents & Percentages \\
\hline Nil & 50 & $50 \%$ \\
\hline Half on hours & 30 & $30 \%$ \\
\hline One hour & 10 & $10 \%$ \\
\hline Two hour & 8 & $8 \%$ \\
\hline More than two hours & 2 & $2 \%$ \\
\hline Total & 100 & $100 \%$ \\
\hline
\end{tabular}

Source: Primary data

Table 1.4 shows that $50 \%$ of respondents are time not spend on online purchasing, $30 \%$ of respondents are spend on half an hour, $10 \%$ of respondents are spend on one hour, $8 \%$ of respondents spend on two hours and only $2 \%$ of respondents are spend on more than two hours respectively.

\section{Kind of online advertisements:}

This table shows that kind of online advertising while purchasing the product through online advertising. Because this is important to know about the advertising. Because this is important to know quality, quantity and other information of the product.

Table 1.5: Kind of online advertisements

\begin{tabular}{|l|l|l|}
\hline Category & No of respondents & Percentages \\
\hline Floating Advertisement & 16 & $16 \%$ \\
\hline E-mail advertisement & 14 & $14 \%$ \\
\hline Popup advertisement & 17 & $17 \%$ \\
\hline Video advertisement & 30 & $30 \%$ \\
\hline Others & 23 & $23 \%$ \\
\hline Total & 100 & $100 \%$ \\
\hline
\end{tabular}

Source: Primary data

Figure 1.5 reveals that $16 \%$ of respondents are used floating advertisement, $14 \%$ of respondents are used E-mail advertisement, $17 \%$ of respondents are used popup advertisement, 30\% of respondents are used video advertisement and finally $23 \%$ of respondents are used other type of advertisement in online advertisement. 
Features of Online advertisement:

\begin{tabular}{|l|l|l|l|l|l|l|l|}
\hline Variables & Excellent & $\begin{array}{l}\text { Very } \\
\text { Good }\end{array}$ & Good & Average & Poor & $\begin{array}{l}\text { Total } \\
\text { Score }\end{array}$ & Rank \\
\hline $\begin{array}{l}\text { Time } \\
\text { consuming }\end{array}$ & $20(100$ & $10(40)$ & $4(12)$ & $2(4)$ & - & 156 & 1 \\
\hline $\begin{array}{l}\text { Collection } \\
\text { of Brand }\end{array}$ & $11(55)$ & $8(32)$ & $3(9)$ & - & $1(1)$ & 97 & 2 \\
\hline Low rate & $9(45)$ & $3(12)$ & $4(12)$ & $2(4)$ & - & 73 & 3 \\
\hline Convenient & $8(40)$ & $2(8)$ & $1(3)$ & - & $1(1)$ & 52 & 4 \\
\hline $\begin{array}{l}\text { Door } \\
\text { delivery }\end{array}$ & $7(35)$ & $2(8)$ & $1(3)$ & - & $1(1)$ & 47 & 5 \\
\hline
\end{tabular}

Source: Primary Data

\section{FINDINGS}

The findings based on the primary data collected are listed here.

- The numbers of respondents who use internet daily for an hour are more as opposed to those who use the internet for two hours and more than two hours.

- Most of the respondents prefer advertised products more than non-advertised products.

- Out of the types of advertisements, online advertisements are preferred most next to television advertisements.

- Out of all the different types of online advertisements, video advertisements are preferred by majority of the respondents.

- It is found out that not many respondents spend time on online purchasing.

- Even though only a few of the respondents have experienced online advertising fraud, almost all of the respondents are aware of online advertising malpractices.

\section{SUGGESTIONS}

- The number of companies advertising online is soaring, but even then fraud and deception may reduce consumer confidence. Therefore, it should be ensured that products and services are described truthfully in online advertisements.

- Trust or confidence can be built in online business by using testimonials with the permission of customers.

- To avoid interference in work, advertisements should be designed to meet the preferences of target customers or target audience.

- Use of multi-media' and use of banner advertisements give viewers a chance to interact with banners which helps in online advertising.

\section{CONCLUSION}

The study titled 'Effectiveness of online advertising' reveals that the most effective media of advertising is online advertising. Internet advertising offers increased awareness of companies, an easy method to distribute information, advanced methods of targeting consumers, an immediate and direct line to the 
customers, and reduced costs in performing these tasks. The main problem related to this is the interference of online advertisements in the work of people and the fear of falling prey to online advertising fraud and malpractice. As people get more accustomed to finding product information on the web, more and more readers will actively seek out Internet advertising sites.

\section{REFERENCES}

[1] Janoschka, Anja — 'Web Advertising' - John Benjamins Publishing, O1Jan-2004

[2] Shimp, Terence and Andrews, Craig J-'Advertising Promotion and Other Aspects of Integrated Marketing Communications' - Ccngage Learning, 16-Jan-2013

[3] The Economic Times:

[4] 'Online Ad Market in India to reach rupees 1000 crore by $2015^{\prime}$ published on 20th February, 2012.

[5] Golden, S. A. R., \& Regi, S. B. Mobile Commerce in Modern Business Era.

[6] 'Getting the Eyeballs' published on 19th July, 2007.

[7] 'Internet Advertising Boom Next in Line' published on 29th March, 2010.

[8] Golden, S. A. R. (2015). Regional Imbalance affecting quality of e-banking services with special reference to Tuticorin District-An Analysis. International Journal of Research, 2(3), 788-798.

[9] 'Why China loves the Internet' published on 18th December, 2013. 